\title{
Effects of fasting during Ramadan on urinary excretion in Malaysian Muslims
}

\author{
BY S. H. CHEA H' ${ }^{1}$, S. L. CH'NG', R. HUSAIN ${ }^{1}$ AND M. T. DUNCAN ${ }^{1}$ \\ Departments of ${ }^{1}$ Physiology and ${ }^{2}$ Pathology, Faculty of Medicine, University of Malaya, \\ 59100 Kuala Lumpur, Malaysia
}

(Received 13 July 1989-Accepted 22 August 1989)

\begin{abstract}
Urine analysis was conducted on male Muslims before, during and after Ramadan. Various changes in urine volume, osmolality, total solute, sodium, potassium, titratable acidity and urea in response to altered feeding and activity regimens were found. There were no detectable levels of ketones, protein, glucose, urobilinogen and haemoglobin. It was concluded that the body adapted to fasting during Ramadan and that there were no adverse effects on renal function.
\end{abstract}

Fasting: Ramadan: Urinary excretion

Total abstention from food and water from sunrise to sunset during the month of Ramadan, which lasts $28-29$ d, is practised by Muslims throughout the world (Sakr, 1975; Husain et al. 1987). The pattern of activity and food deprivation or 'fasting' during Ramadan is different from the usual 'fasting' or food deprivation which has been widely studied (Rapoport et al. 1965; Johnson et al. 1971; Weinsier, 1971 ; Drenick, 1980). To date only limited studies on the physiological effects of altered activity and feeding schedule during Ramadan (fasting) have been conducted (Gumaa et al. 1978; Mustafa et al. 1978; Husain et al. 1987).

The present study examines the effects of fasting during Ramadan on Malaysian Muslims with regard to several urinary variables, including urine output and osmolality, and total solute, sodium ions, potassium ions and urea excretion. Semi-quantitative measurements using reagent strips were also carried out to determine the urinary concentrations of ketones, protein, glucose, urobilinogen and haemoglobin.

\section{METHODS}

Twenty male Malaysian Muslims, aged between 20 and 45 years and engaged mainly in sedentary activity, volunteered for the present study. All subjects gave their informed consent to participate in the project.

Urine samples $(24 \mathrm{~h})$ were collected from the subjects $2-3 \mathrm{~d}$ before the start of fasting (Pr), and once weekly during the fasting period (R1-R4). Samples were also collected at 1 week (PO1) and 4-5 weeks (PO2) following the end of Ramadan. The collection of the $24 \mathrm{~h}$ urine was divided into three periods: (1) morning, 08.00-12.00 hours; (2) afternoon, 12.00-16.00 hours; and (3) overnight, 16.00-08.00 hours of the following day. Urine was collected into screw-capped plastic bottles containing $0 \cdot 1-0 \cdot 2 \mathrm{ml}$ of $1 \%$ sodium azide as preservative. Measurement of urine volume, osmolality (Osmette A automatic osmometer; Precision Systems Inc, Sudbury, MA, USA), titratable acidity (Varley et al. 1980) and the strip tests (Combur ${ }^{6}$-test; Boehringer Mannheim, Mannheim, West Germany) were conducted immediately on receipt of the samples. Portions of each urine sample were also stored at $-20^{\circ}$ for subsequent measurement of $\mathrm{Na}^{+}, \mathrm{K}^{+}$and urea using a Technicon SMA II AutoAnalyzer (Technicon Inc., Tarrytown, New York). 


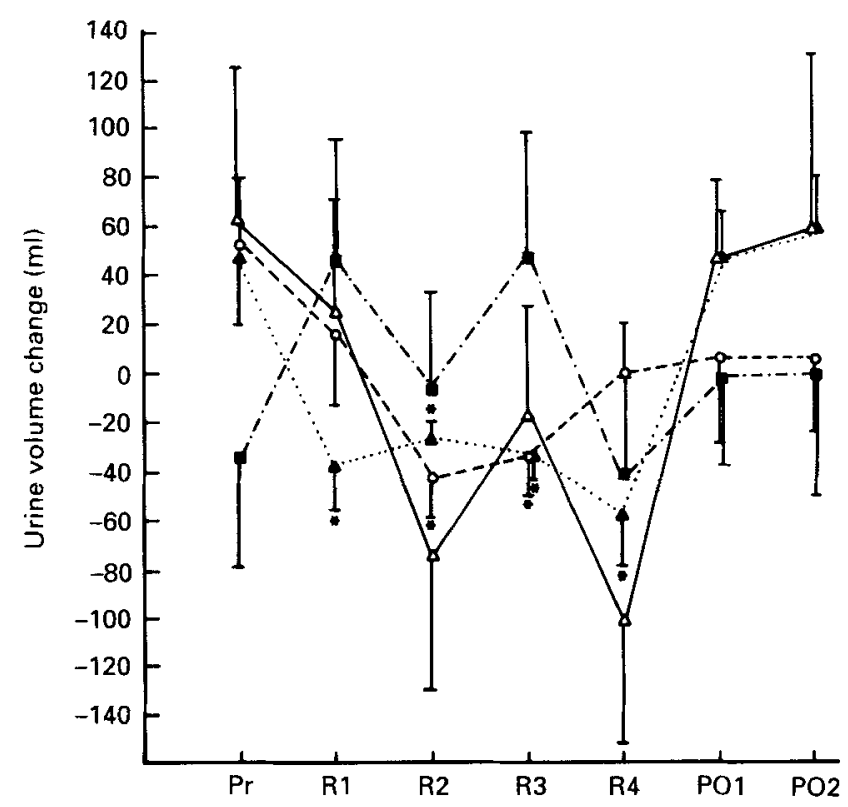

Fig. 1. Changes in urine volume excreted before, during and after Ramadan in Malaysian Muslims. Calculations are described on p. 330. ( $\bigcirc--\bigcirc)$, Morning (08.00-12.00 hours) collection; $(\boldsymbol{\Delta} \cdots \mathbf{A})$, afternoon $(12.00-16.00$ hours) collection; ( $\square--\square)$, overnight (16.00 08.00 hours) collection; $(\triangle-\triangle)$, total $(24 \mathrm{~h})$ urine. Values are means with their standard errors represented by vertical bars. Pr, pre-Ramadan; R1, R2, R3 and R4 are 1st, 2 nd, 3rd and 4th weeks of Ramadan respectively; PO1, 1 week post-Ramadan; PO2, 4-5 weeks post-Ramadan. ${ }^{*}$ Mean values were significantly different $(P<0.05)$ from pre-Ramadan levels.

The changes in urine volume output, and excretion of $\mathrm{Na}^{+}, \mathrm{K}^{+}$, titratable acidity and osmotically active substances for each subject were calculated throughout the period of study by determining the overall mean $\left(X_{t}\right)$ for that subject and subtracting it from the individual values obtained during each collection $\left(X_{n}\right.$, where $n=\operatorname{Pr}, \mathrm{R} 1, \mathrm{R} 2$, R3, etc.), i.e. $X_{n}-X_{t}$. The mean change for each period was determined and the significance tested using Student's paired $t$ test. Values of thirteen subjects who presented complete sets of values were subjected to this treatment.

\section{RESULTS}

Urine output before, during and after the month of Ramadan is shown in Fig. 1. Although the $24 \mathrm{~h}$ urine output during Ramadan tended to be lower than that of the pre-fasting level, the decline was not significant (Fig. 1). When the $24 \mathrm{~h}$ urine output was divided into three periods there was essentially no change in the overnight output. On the other hand, there was a significant decline in the volume for the morning samples in the 2 nd and $3 \mathrm{rd}$ weeks of fasting; however, the output seemed to recover thereafter, so that the decline was not statistically significant by the last week of fasting. The urine output during the afternoon was depressed significantly throughout the fasting period, but recovered quickly to control levels within 1 week after the cessation of fasting. Two subjects in the 1st week of fasting, one subject in the 2 nd week and three subjects in the 4 th (final) week failed to present any urine in the afternoon collection.

The total amount of solute excreted in $24 \mathrm{~h}$ was lower during the fasting month; solute excretion returned to pre-fasting levels following the cessation of fasting (Fig. 2). Solute 


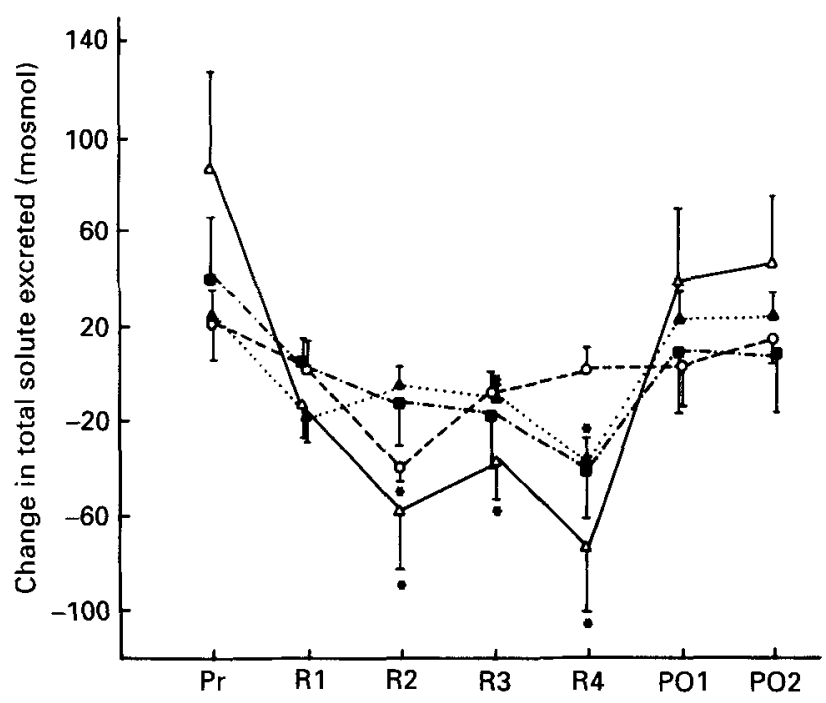

Fig. 2. Changes in total solute excreted in urine before, during and after Ramadan in Malaysian Muslims. (O-- O), Morning (08.00-12.00 hours) collection; $(\boldsymbol{\Delta} \cdots \mathbf{\Delta})$, afternoon (12.00-16.00 hours) collection; $(\mathbf{\square} \cdots \mathbf{D}$ ), overnight (16.00-08.00 hours) collection; $(\triangle-\Delta)$, total $(24 \mathrm{~h})$ urine. Values are means with their standard errors represented by vertical bars. Pr, pre-Ramadan; R1, R2, R3 and R4 are 1st, 2nd, 3rd and 4th weeks of Ramadan respectively; PO1, 1 week post-Ramadan; PO2, 4-5 weeks post-Ramadan. * Mean values were significantly different $(P<0.05)$ from pre-Ramadan levels.

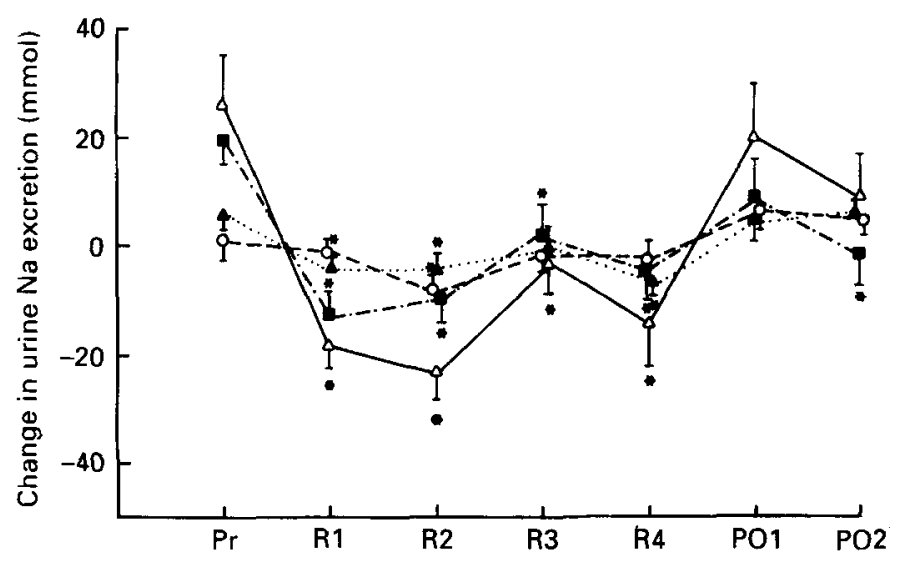

Fig. 3. Changes in urine sodium excretion before, during and after Ramadan in Malaysian Muslims. (O--- $\bigcirc$ ), Morning (08.00-12.00 hours) collection; $(\boldsymbol{\Delta} \cdots \mathbf{\Delta})$, afternoon (12.00-16.00 hours) collection; ( $\mathbf{\square}-\boldsymbol{\square})$, overnight (16.00-08.00 hours) collection; $(\triangle-\triangle)$, total $(24 \mathrm{~h})$ urine. Values are means with their standard errors represented by vertical bars. Pr, pre-Ramadan; R1, R2, R3 and R4 are 1st, 2nd, 3rd and 4th weeks of Ramadan respectively; PO1, 1 week post-Ramadan; PO2, 4-5 weeks post-Ramadan. * Mean values were significantly different $(P<0.05)$ from pre-Ramadan levels.

excretion during the overnight and afternoon periods was generally depressed during Ramadan, with the lowest excretion during the final week, whereas the excretion in the morning was lowest during the 2 nd week of fasting, with levels recovering to control levels thereafter.

Total $24 \mathrm{~h} \mathrm{Na}^{+}$output declined significantly throughout the fasting period, the decline 


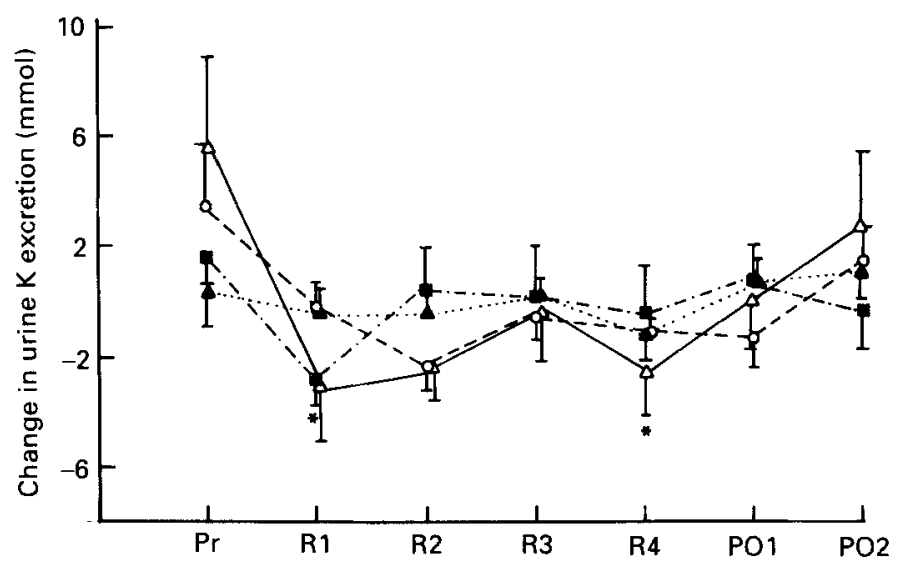

Fig. 4. Changes in urine potassium excretion before, during and after Ramadan in Malaysian Muslims. ( $\mathrm{O}---\mathrm{O})$, Morning (08.00-12.00 hours) collection; $(\mathbf{\Delta} \cdots \mathbf{A})$, afternoon (12.00-16.00 hours) collection; ( $\boldsymbol{\square}-\cdots)$, overnight (16.00-08.00 hours) collection; $(\triangle-\triangle)$, total $(24 \mathrm{~h})$ urine. Values are means with their standard errors represented by vertical bars. Pr, pre-Ramadan; R1, R2, R3 and R4 are 1st, 2nd, 3rd and 4th weeks of Ramadan respectively; PO1, 1 week post-Ramadan; PO2, 4-5 weeks post-Ramadan. * Mean values were significantly different $(P<0.05)$ from pre-Ramadan levels.

being greatest during the first 2 weeks of Ramadan (Fig. 3). There was a slight increase thereafter, with a strong rebound in the lst week post-Ramadan. Overnight $\mathrm{Na}^{+}$output also declined throughout Ramadan. The output increased in the 1st week post-Ramadan; however, the output 1 month after Ramadan was significantly lower than pre-fasting levels. The output during the afternoon was significantly lower throughout Ramadan, except for the 3rd week, while the output in the morning was generally unchanged during fasting, except for a decrease in the 2nd week.

In general, the change in $\mathrm{K}^{+}$output during Ramadan was less dramatic compared with the $\mathrm{Na}^{+}$output (Fig. 4). There was some decline in $\mathrm{K}^{+}$output in the $24 \mathrm{~h}$ urine, but this was significant only in the 4 th week of fasting. Except for a significant decline in the 1 st week of fasting in the overnight collection, there were no significant changes in the morning, afternoon and most of the overnight output during Ramadan.

Titratable acidity in $24 \mathrm{~h}$ urine declined significantly during Ramadan (Fig. 5). This decrease was mainly attributable to the lower titratable acidity excreted during the overnight period.

The mean osmolality, and concentrations of $\mathrm{Na}^{+}$and $\mathrm{K}^{+}$in all the collected morning, afternoon and overnight samples (including from those subjects who missed one session or more) is shown in Table 1 . Osmolality in the morning and afternoon increased during Ramadan, as might be expected during a period of decreased volume excretion. The osmolality fluctuated without a discernible pattern in the overnight collections.

The concentrations of $\mathrm{Na}^{+}$and $\mathrm{K}^{+}$were not consistently increased during Ramadan even during the morning and afternoon when urine volumes tended to be decreased, and mostly were maintained near or even below pre-fasting levels.

Urine urea concentrations in all morning, afternoon and overnight samples increased and generally stayed above pre-fasting levels throughout Ramadan (Fig. 6(a)). The estimated portion of urine osmolality $\left(\mathrm{Osm}_{\mathrm{f}}\right)$ contributed by urea and $\mathrm{Na}^{+}$and $\mathrm{K}^{+}$salts throughout the period of measurement is shown in Fig. $6(b)$. The changes in Osm $\mathrm{f}_{\mathrm{f}}$ of the morning and overnight samples nearly paralleled the changes in urine osmolality (Table 1), 


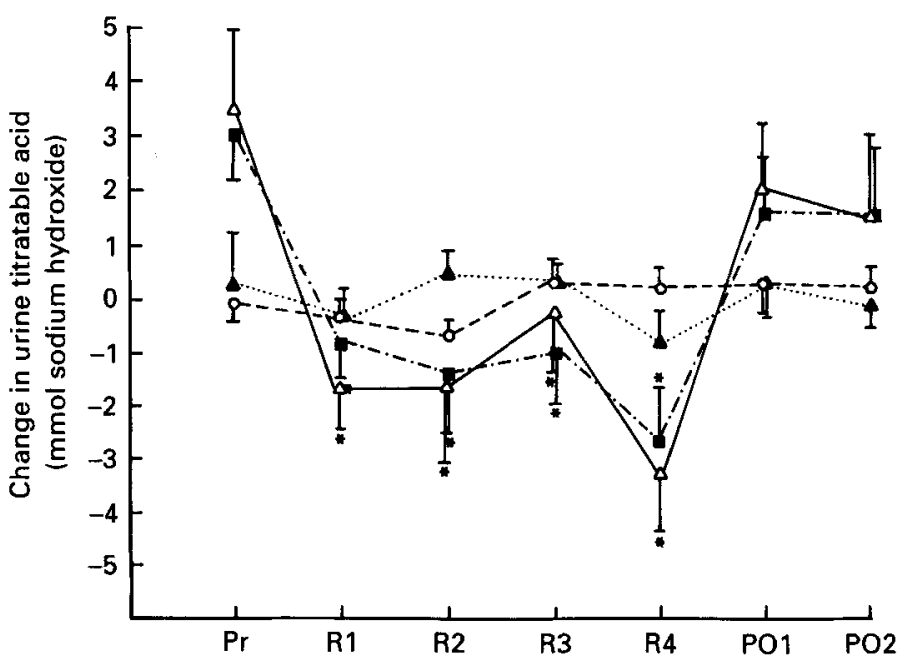

Fig. 5. Changes in urine titratable acid before, during and after Ramadan in Malaysian Muslims. (O-- 0 ), Morning (08.00-12.00 hours) collection; $(\mathbf{A} \cdots \mathbf{\Delta})$, afternoon (12.00-16.00 hours) collection; ( $\mathbf{\square} \cdot-\mathbf{D})$, overnight (16.00-08.00 hours) collection; $(\triangle-\triangle)$, total $(24 \mathrm{~h})$ urine. Values are means with their standard errors represented by vertical bars. Pr, pre-Ramadan; R1, R2, R3 and R4 are 1st, 2nd, 3rd and 4th weeks of Ramadan respectively; PO1, 1 week post-Ramadan; $\mathrm{PO} 2,4-5$ weeks post-Ramadan. * Mean values were significantly different $(P<0.05)$ from pre-Ramadan levels.

whereas the changes of $\mathrm{Osm}_{\mathrm{f}}$ in the afternoon samples in general differed from the variations in urine osmolality.

Protein, glucose, urobilinogen, ketones, and haemoglobin were not detected in any urine sample throughout the period of the study.

\section{DISCUSSION}

The results show that the altered activity and feeding schedules during the month of Ramadan induced several changes in urine output and content.

Although there was some decline in the $24 \mathrm{~h}$ urine output, this was not significant, mainly because the overnight urine output remained essentially unchanged; only the afternoon output was consistently less than pre-fasting levels throughout Ramadan. In the morning collections, after an early decline during the first 2 weeks of Ramadan, the output increased again. These results indicate that the subjects were probably not subjected to severe stress of water deprivation during the month of Ramadan. The body adapted well to the lack of water during the day, and significant water conservation occurred only in the afternoon. The high ambient temperature of up to an average of $31^{\circ}$ in the afternoon (Ooi \& Chia, 1974) resulting in continuous water loss by sweat production, as well as the prolonged time interval of greater than $7-8 \mathrm{~h}$ since the last fluid ingestion, are contributing factors to increased renal water re-absorption and low urine volume in the afternoon collection. These results are consistent with the observation that Malaysian Muslims are essentially in water balance even during the period of fasting (Husain et al. 1987). These results are also comparable to the findings of Mustafa et al. (1978) in their Sudanese subjects which showed that urine output remained high at night, while daytime urine volumes showed a decrease.

The results for $\mathrm{Na}^{+}$and $\mathrm{K}^{+}$excretion are at some variance with the findings of Mustafa et al. (1978) for their Sudanese subjects. They reported that while $\mathrm{Na}^{+}$excretion during the 
Table 1. Osmolality and concentrations of sodium and potassium ions in morning, afternoon and overnight urine samples taken from Malaysian Muslim subjects before (Pr), during (R1-R4) and after (PO1 and PO2) Ramadan

(Mean values with their standard errors for no. of samples available*)

\begin{tabular}{|c|c|c|c|c|c|c|c|c|c|}
\hline & & & $\operatorname{Pr}$ & $\mathbf{R} \mathbf{l}$ & R2 & R3 & R4 & POI & $\mathrm{PO} 2$ \\
\hline $\begin{array}{l}\text { Osmolality } \\
\text { (mosmol/kg) }\end{array}$ & Afternoon & $\begin{array}{l}\text { Mean } \\
\mathrm{SE} \\
n \\
\text { Mean } \\
\mathrm{SE} \\
n \\
\text { Mean } \\
\mathrm{SE} \\
n\end{array}$ & $\begin{array}{c}683 \cdot 2 \\
65 \cdot 12 \\
18 \\
753 \cdot 9 \\
44 \cdot 11 \\
18 \\
794 \cdot 1 \\
48 \cdot 99 \\
18\end{array}$ & $\begin{array}{c}749 \cdot 4 \\
60 \cdot 57 \\
19 \\
873 \cdot 8 \\
38 \cdot 28 \\
17 \\
703 \cdot 2 \\
69 \cdot 99 \\
19\end{array}$ & $\begin{array}{c}831 \cdot 4 \\
60 \cdot 59 \\
20 \\
936 \cdot 8 \\
28 \cdot 18 \\
18 \\
737 \cdot 2 \\
57 \cdot 71 \\
20\end{array}$ & $\begin{array}{c}784 \cdot 9 \\
42 \cdot 98 \\
19 \\
848 \cdot 9 \\
26 \cdot 33 \\
18 \\
645 \cdot 8 \\
60 \cdot 56 \\
20\end{array}$ & $\begin{array}{c}778 \cdot 9 \\
65 \cdot 69 \\
16 \\
872 \cdot 7 \\
45 \cdot 54 \\
13 \\
780 \cdot 9 \\
62 \cdot 86 \\
18\end{array}$ & $\begin{array}{c}707 \cdot 7 \\
56.08 \\
18 \\
749 \cdot 0 \\
49.95 \\
17 \\
718.6 \\
55.45 \\
19\end{array}$ & $\begin{array}{c}783 \cdot 2 \\
45 \cdot 52 \\
18 \\
739 \cdot 2 \\
50 \cdot 01 \\
16 \\
642 \cdot 6 \\
56 \cdot 84 \\
18\end{array}$ \\
\hline $\mathrm{Na}^{+}(\mathrm{mmol} / \mathrm{l})$ & $\begin{array}{l}\text { Morning } \\
\text { Afternoon }\end{array}$ & $\begin{array}{l}\text { Mean } \\
\text { SE } \\
n \\
\text { Mean } \\
\text { SE } \\
n \\
\text { Mean } \\
\text { SE } \\
n\end{array}$ & $\begin{array}{c}118 \cdot 9 \\
14 \cdot 03 \\
18 \\
139 \cdot 5 \\
14 \cdot 05 \\
18 \\
162 \cdot 72 \\
9 \cdot 74 \\
18\end{array}$ & $\begin{array}{l}111 \cdot 0 \\
12 \cdot 38 \\
19 \\
111 \cdot 9 \\
12 \cdot 66 \\
17 \\
89 \cdot 9 \\
14 \cdot 44 \\
19\end{array}$ & $\begin{array}{c}107 \cdot 3 \\
12.08 \\
20 \\
98 \cdot 3 \\
7 \cdot 61 \\
19 \\
119 \cdot 9 \\
10 \cdot 42 \\
20\end{array}$ & $\begin{array}{c}137 \cdot 0 \\
12 \cdot 57 \\
19 \\
150 \cdot 3 \\
10 \cdot 69 \\
18 \\
117 \cdot 1 \\
12 \cdot 65 \\
20\end{array}$ & $\begin{array}{c}112 \cdot 9 \\
15 \cdot 26 \\
16 \\
137 \cdot 9 \\
11 \cdot 96 \\
13 \\
143 \cdot 5 \\
16 \cdot 42 \\
17\end{array}$ & $\begin{array}{c}155 \cdot 8 \\
15 \cdot 05 \\
18 \\
173 \cdot 9 \\
13 \cdot 12 \\
17 \\
139 \cdot 9 \\
10 \cdot 26 \\
19\end{array}$ & $\begin{array}{c}136 \cdot 8 \\
11 \cdot 16 \\
18 \\
128 \cdot 7 \\
10 \cdot 66 \\
16 \\
102 \cdot 4 \\
12 \cdot 22 \\
18\end{array}$ \\
\hline $\mathrm{K}^{+}(\mathrm{mmol} / \mathrm{l})$ & Afternoon & $\begin{array}{l}\text { Mean } \\
\text { SE } \\
n \\
\text { Mean } \\
\text { SE } \\
n \\
\text { Mean } \\
\text { SE } \\
n\end{array}$ & $\begin{array}{l}54 \cdot 7 \\
15 \cdot 04 \\
18 \\
38 \cdot 4 \\
5 \cdot 28 \\
18 \\
32 \cdot 9 \\
3 \cdot 00 \\
18\end{array}$ & $\begin{array}{c}38 \cdot 4 \\
4 \cdot 43 \\
19 \\
46 \cdot 9 \\
5 \cdot 56 \\
18 \\
25 \cdot 9 \\
5 \cdot 10 \\
19\end{array}$ & $\begin{array}{c}39 \cdot 0 \\
4 \cdot 43 \\
20 \\
43 \cdot 5 \\
3 \cdot 72 \\
20 \\
28 \cdot 8 \\
3 \cdot 45 \\
20\end{array}$ & $\begin{array}{c}42 \cdot 7 \\
4 \cdot 69 \\
19 \\
55 \cdot 8 \\
5 \cdot 48 \\
18 \\
21 \cdot 3 \\
2 \cdot 82 \\
20\end{array}$ & $\begin{array}{c}36 \cdot 8 \\
4 \cdot 65 \\
16 \\
62 \cdot 8 \\
5 \cdot 09 \\
13 \\
30 \cdot 3 \\
3 \cdot 40 \\
17\end{array}$ & $\begin{array}{c}27 \cdot 0 \\
3 \cdot 18 \\
18 \\
38 \cdot 1 \\
3 \cdot 73 \\
17 \\
26 \cdot 7 \\
2 \cdot 86 \\
19\end{array}$ & $\begin{array}{c}40 \cdot 9 \\
3 \cdot 88 \\
18 \\
33 \cdot 5 \\
4 \cdot 00 \\
16 \\
20 \cdot 9 \\
2 \cdot 12 \\
18\end{array}$ \\
\hline
\end{tabular}

* Subjects who were unable to provide any urine were not included in the calculations.

day was decreased $\mathrm{Na}^{+}$output during the night was unchanged during Ramadan. On the other hand, $\mathrm{K}^{+}$excretion was decreased during the day and increased during the night, giving an unchanged $24 \mathrm{~h}$ output. The reason for this difference is not clear, and could be the result of different dietary, cultural and climatic conditions.

The decrease in $\mathrm{Na}^{+}$excretion in Malaysian Muslims during Ramadan is consistent with that found in subjects undergoing energy restriction (Rapoport et al. 1965; Conzolasio et al. 1968; Drenick, 1980). However, whether the body was in $\mathrm{Na}^{+}$balance is not known, since electrolyte intake was not monitored; but it is likely that electrolyte intake was reduced since food intake was reduced by about $20 \%$ during Ramadan (Husain et al. 1987). The mechanism for the control of urinary $\mathrm{Na}^{+}$excretion during and after Ramadan is probably quite complex, and factors including aldosterone, atrial natriuretic factor (ANF) and tubuloglomerular balance, which are in turn influenced by neural, hormonal and humoral factors (Early \& Schrier, 1973; O'Connor, 1977; Hall et al. 1980; Moss, 1982; Carey \& Sen, 1986; Atlas \& Laragh, 1986) may be involved. The observation that overnight $\mathrm{Na}^{+}$excretion was significantly lower 1 month after the end of Ramadan in spite of the return to normal feeding regimens was unexpected. The reason for this is not known. A recent study (Cooke et al. 1987) found that following the cessation of energy restriction, 


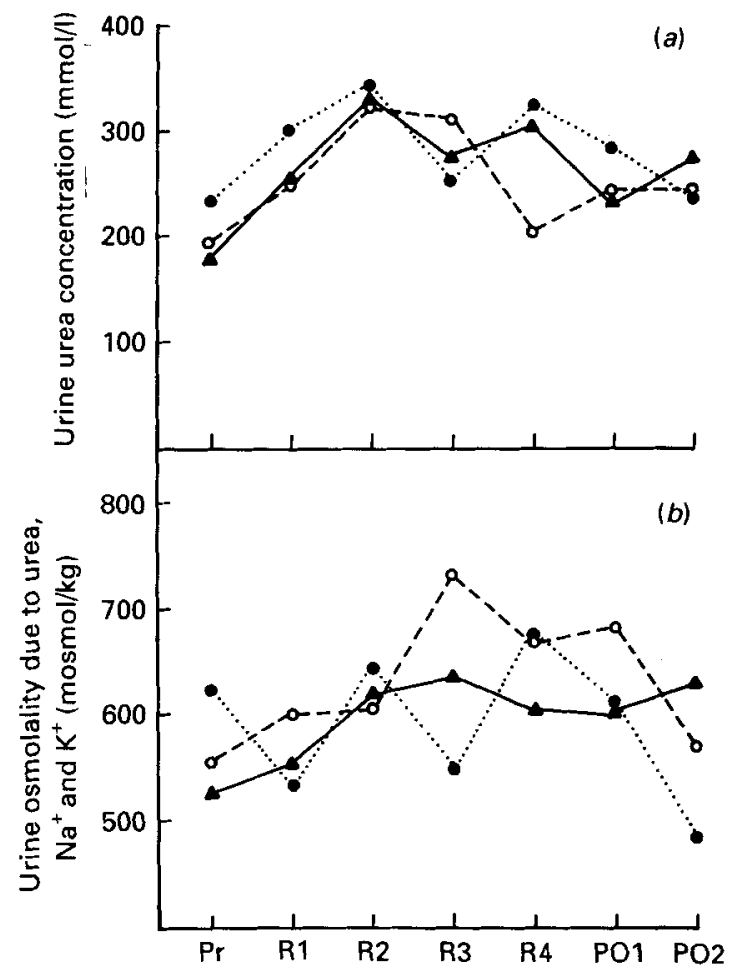

Fig. 6. (a) Urine urea concentrations and $(b)$ the portion of urine osmolality contributed by urea, and sodium and potassium salts before, during and after Ramadan in Malaysian Muslims. The urine osmolality contributed by these substances was calculated by the following formula: urea $+\left[2 \times\left(\mathrm{Na}^{+}+\mathrm{K}^{+}\right)\right]$, where $\mathrm{Na}^{+}+\mathrm{K}^{+}$concentrations are expressed in $\mathrm{mmol} / \mathrm{l}$. It was assumed that the main salts were sodium chloride and potassium chloride (Free \& Free, 1975). Values were pooled from all available urine samples. Collections where subjects were unable to produce any urine were not included. (A- $\mathbf{A})$, Morning (08.00-12.00 hours); (O-- $\bigcirc)$, afternoon (12.00-16.00 hours); ( $\cdots$ ), overnight (16.00-08.00 hours). Pr, pre-Ramadan; R1, R2, R3 and R4 are 1st, 2nd, 3rd and 4th weeks of Ramadan respectively; PO1, 1 week post-Ramadan; PO2, 4-5 weeks post-Ramadan.

decreased urinary excretion of $\mathrm{Na}^{+}$occurred for up to 1 month afterwards. The mechanism for this phenomenon is not known. It is possible that the continued lowered overnight $\mathrm{Na}^{+}$ excretion after Ramadan may be due to a similar mechanism. Why it only occurs at night and not during the day is uncertain. However, it should be noted that in Ramadan the food restriction is less severe than in the previously mentioned study, and that it only occurs in the daylight hours, and this could have modified the post-fast lowered $\mathrm{Na}^{+}$excretion phenomenon. The decreased excretion of $\mathrm{Na}^{+}$in the overnight period was partly compensated by recovered $\mathrm{Na}^{+}$excretion in the morning and afternoon, and thus, on a $24 \mathrm{~h}$ basis, $\mathrm{Na}^{+}$excretion in the pre-fast and post-fast periods is not different.

$\mathrm{K}^{+}$output did not change as dramatically as $\mathrm{Na}^{+}$, although $\mathrm{K}^{+}$intake was probably also decreased. This could have been due to the enhanced $\mathrm{K}^{+}$secretion in the distal tubule in exchange for greater $\mathrm{Na}^{+}$re-absorption (Thier, 1986).

The decline in total titratable acidity and an absence of ketonuria suggests that ketoacidosis was not a feature of fasting during Ramadan in the male subjects. This is further supported by the fact that respiratory exchange ratio in the male does not change during Ramadan (Husain et al. 1987) and, thus, any adipose tissue breakdown that might have occurred must have been relatively slow. There was also a decrease in urine inorganic 
phosphorus excretion (S. H. Cheah, S. L. Ch'ng, R. Husain and M. T. Duncan, unpublished results) and the decline in titratable acidity may have been partly due to the decreased urine phosphate excretion which contributes to the urine titratable acid excretion (Cohen \& Kassirer, 1980). The reason why most of the decline in titratable acid occurred during the night is not clear. It could be partly due to the fact that urine $\mathbf{P}$ (and presumably phosphate) declined most greatly in the overnight samples.

The ability of the kidneys to excrete a relatively highly concentrated urine in the daytime shows that the body adapted adequately to the water deprivation during the day and that the concentrating ability of the kidneys remained unimpaired during Ramadan. On the other hand, the relatively constant osmolality exhibited by the overnight samples throughout the experimental period shows that the subjects were adequately rehydrated during the night period. The osmolality of urine is in large part determined by the concentrations of urea, sodium chloride and potassium chloride (Free \& Free, 1975). $\mathrm{Na}^{+}$ concentration in the urine declined in the first half of Ramadan in both the afternoon and overnight samples. During these intervals, the $\mathrm{Na}^{+}$concentrations declined in spite of decreased (afternoon) or relatively constant (overnight) urine output, indicating that $\mathrm{Na}^{+}$ was being actively re-absorbed by the kidneys. In the overnight and morning collections the decline in $\mathrm{Na}^{+}$concentration and its contribution to the urine osmolality was generally compensated for by the increase in urine urea concentration and, thus, the changes in Osm $_{\mathrm{f}}$ paralleled the changes of total urine osmolality (Fig. 6(b) and Table 1). In fact, the increase in urine osmolality in the morning samples during Ramadan could be associated with an increase in urine urea concentration. The lack of correlation in the afternoon urine between the changes in total osmolality and $\mathrm{Osm}_{\mathrm{f}}$ suggests that increases in urea concentration did not fully account for the changes in urine osmolality seen during Ramadan, and that some other yet undetermined substance(s) may be involved.

The regimen of altered feeding and activity had apparently no adverse effect on kidney function. Besides the ability to adjust the excretion of water and material throughout the day during and following Ramadan, there was no detectable urobilinogen, protein, or haemoglobin in the urine. Serum creatinine and urea measured in some subjects during mid- and the final week of fasting showed no increase from pre- or post-fasting levels; serum $\mathrm{Na}^{+}$and $\mathrm{K}^{+}$also showed no gross changes beyond accepted normal values (S. H. Cheah, S. L. Ch'ng, R. Husain and M. T. Duncan, unpublished results). Thus, the integrity of kidney function appears to be intact.

The results presented indicate that fasting in Ramadan does not provoke the degree of changes in urinary output and electrolyte content as does strict and prolonged restriction of energy input (Rapoport et al. 1965; Weinsier, 1971; Drenick, 1980). This could be due to the fact that food and water are available $a d$ lib. between sunset and sunrise, and this generally compensates for their lack during the day. The body appears to adapt well to lack of water and food during the day, and to the presumed reduced intake of $\mathrm{Na}^{+}$and $\mathrm{K}^{+}$ throughout Ramadan with appropriate reduced solute and electrolyte output especially in the afternoon and night. Overnight $\mathrm{Na}^{+}$excretion increased again after a maximum decrease in the 2 nd week of fasting, and overnight $\mathrm{Na}^{+}$excretion failed to return to prefasting levels even 1 month after Ramadan for reasons that can only be speculated upon at this time. There was no evidence of ketoacidosis since ketone concentrations in the urine were below the level of detection, and titratable acidity of the urine was reduced. There was generally no apparent adverse effect on kidney function. 


\section{REFERENCES}

Atlas, S. A. \& Laragh, J. H. (1986). Atrial natriuretic peptide: a new factor in hormonal control of blood pressure and electrolyte homeostasis. Annual Review of Medicine 37, 397-414.

Carey, R. M. \& Sen, S. (1986). Recent progress in the control of aldosterone secretion. Recent Progress in Hormone Research 42, 251-296.

Cohen, J. J. \& Kassirer, J. P. (1980). Acid-base metabolism. In Clinical Disorders of Fluid and Electrolyte Metabolism, 3rd ed, pp. 181-232 [M. H. Maxwell and C. R. Kleeman, editors]. New York: McGraw-Hill.

Conzolasio, C. F., Matoush, L. O., Johnson, H. L., Krzywicki, H. J., Isaac, G. J. \& Witt, N. F. (1968). Metabolic aspects of calorie restriction: nitrogen and mineral balances and vitamin excretion. American Journal of Clinical Nutrition 21, 803-812.

Cooke, C. R., Turin, M. D., Whelton, A. \& Walker, W. G. (1987). Studies of marked and persistent sodium retention in previously fasted and sodium-deprived obese subjects. Metabolism 36, 609-615.

Drenick, E. J. (1980). The effects of acute and prolonged fasting and refeeding on water, electrolyte, and acid-base metabolism. In Clinical Disorders of Fluid and Electrolyte Metabolism, 3rd ed., pp. 1481-1501 [M. H. Maxwell and C. R. Ḱleeman, editors]. New York: McGraw-Hill.

Early, L. E. \& Schrier, R. W. (1973). Intrarenal control of sodium by hemodynamic and physical factors. In Handbook of Physiology. Renal Physiology, pp. 721-762 [J. Orloff and R. W. Berliner, editors]. Washington, DC: American Physiological Society.

Free, A. H. \& Free, H. M. (1975). Urinalysis in Clinical Laboratory Practice, pp. 13-19. Cleveland, Ohio: CRC Press.

Gumaa, K. A., Mustafa, K. Y., Mahmoud, N. A. \& Gader, A. M. A. (1978). The effects of fasting in Ramadan. 1. Serum uric acid and lipid concentrations. British Journal of Nutrition 40,573-581.

Hall, J. E., Guyton, A. C., Smith, M. J. \& Coleman, T. G. (1980). Blood pressure and renal function during changes in sodium intake: the role of angiotensin. American Journal of Physiology 239, 271-280.

Husain, R., Duncan, M. T., Cheah, S. H. \& Ch'ng, S. L. (1987). Effects of fasting in Ramadan on tropical Asiatic Moslems. British Journal of Nutrition 58, 41-48.

Johnson, H. L., Consolazio, C. F., Krzywicki, H. J., Isaac, G. J. \& Witt, N. F. (1971). Metabolic aspects of caloric restriction: nutrient balances with 500-calorie intakes. American Journal of Clinical Nutrition 24, 913-923.

Moss, N. G. (1982). Renal function and renal afferent and efferent nerve activity. American Journal of Physiology 243, 423-433.

Mustafa, K. Y., Mahmoud, N. A., Gumaa, K. A. \& Gader, A. M. A. (1978). The effects of fasting in Ramadan. 2. Fluid and electrolyte balance. British Journal of Nutrition 40, 583-594.

O'Connor, W. J. (1977). Normal sodium balance in dogs and man. Cardiovascular Research 11, 375-408.

Ooi, J. B. \& Chia, L. S. (1974). The Climate of West Malaysia and Singapore. London: Oxford University Press.

Rapoport, A., From, G. L. A. \& Husdan, H. (1965). Metabolic studies in prolonged fasting. I. Inorganic metabolic and kidney functions. Metabolism 14, 31- 46.

Sakr, A. H. (1975). Fasting in Islam. Journal of the American Diabetic Association 67, 17-21.

Thier, S. O. (1986). Potassium physiology. American Journal of Medicine 80, Suppl. 4A, 3-7.

Varley, H., Gowenlock, A. H. \& Bell, M. (1980). Practical Clinical Biochemistry, vol. 1. London: William Heinemann.

Weinsier, R. L. (1971). Fasting - a review with emphasis on electrolytes. American Journal of Medicine 50, 233-239. 